\author{
Accelerator Division \\ Alternating Gradient Synchrotron Department \\ BROOKHAVEN NATIONAL LABORATORY \\ Associated Universities, Inc. \\ Upton, NY 11973 \\ Accelerator Division \\ Technical Note \\ AGS/AD/Tech. Note No. 315
}

\title{
THE STRETCHER VACUUM SYSTEM
}

\author{
Kimo M. Welch and Joseph E. Tuozzolo
}

February 13, 1989

\section{Introduction}

The dipole magnets will be $\approx 7.33 \mathrm{~m}$ long. There will be 68 of these in the main Stretcher. Comparable dipole magnets are used to blend the geometries of the Stretcher and the AGS and vertically bend the beam to compensate for their different elevations. It is assumed an additional ten dipole magnets, with identical chambers, will serve these purposes. It is further assumed that, with the exception of the main seals of the Sector and Roughing Valves, the Stretcher will be an all-metal system.

The number and length of the dipole magnets are important in defining the width of the vacuum chamber. Use of a single segment vs multi-segment magnet doesn't impact on this width, as long as the field is near-uniform over the magnet length. Each chamber will be butt-welded in three sections. For reasons discussed in the following section, the chamber walls will have to be bowed to form an interference fit with the dipole magnet faces. It is not advisable to attempt to bend or shape the chambers to the beam radius of curvature, under these circumstances.

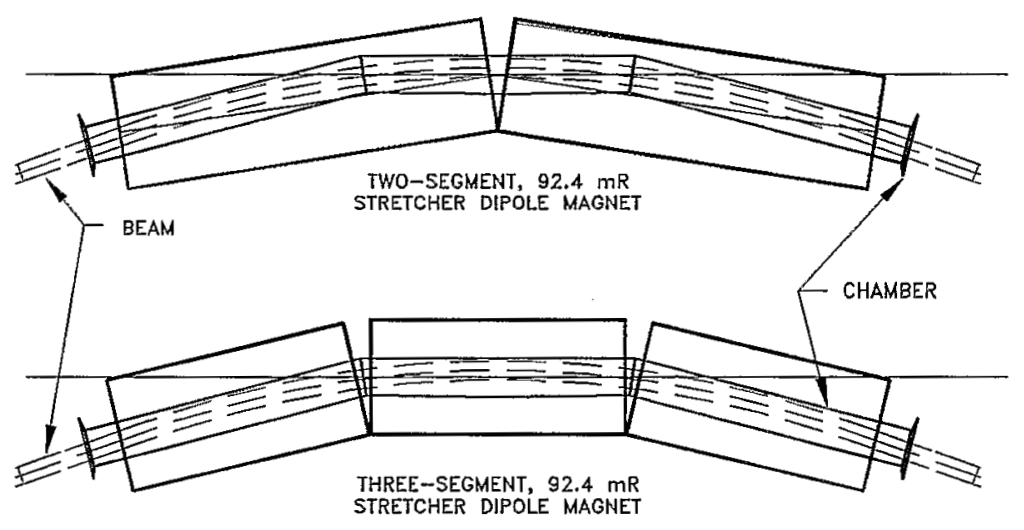

Figure 1. Three-Segement Beam Chamber In Multi-Segment Dipole Magnets. 


\section{Dipole Magnet Chamber Cross-Section}

Because of the narrow vertical aperture (i.e., $\approx 41.3 \mathrm{~mm}$ ), chambers in the dipole magnets will have to be prestressed. The equations for the wall deflection at the center of the chamber, $\mathbf{y}$, and the maximum stress, $\mathbf{s}$, of the major chamber width are as follows:

$$
\begin{aligned}
& \mathbf{y}=\frac{\mathbf{p}}{\mathbf{E} \mathbf{t}^{3}}\left[\frac{5 \mathrm{w}^{4}}{32}+\frac{\left(\mathrm{h}^{3}+\mathrm{w}^{3}\right) \mathrm{w}^{2}}{8(w+h)}\right], \\
& S=\frac{P\left(h^{3}+w^{3}\right)}{t^{2}(w+h)}, \\
& \mathbf{E}=\text { the modulus of elasticity, } \mathrm{Lb} / \mathrm{in}^{2} \text {. }
\end{aligned}
$$

For a chamber of cross-section comparable to dimensions given in Fig. 2, and neglecting the effects of the radii at the corners, the maximum deflection at the center of the chamber, $\mathbf{y}_{\mathfrak{m}}$, as a consequence of atmospheric pressure, and the stress, $\mathbf{s}$, are given for a stainless steel chamber in Tables I \& II, respectively, and for an Al chamber in Tables III \& IV.

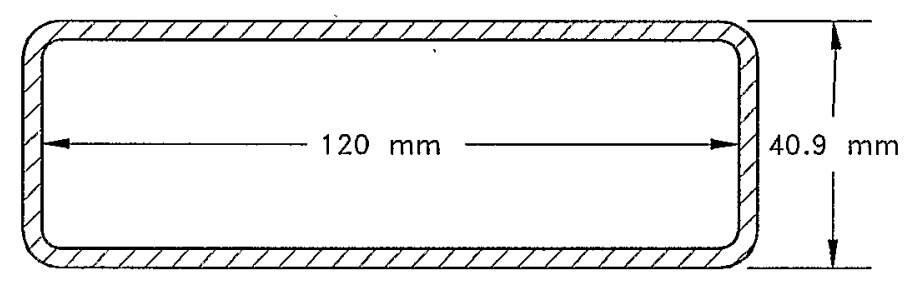

The effects of external pressure on the chamber deflection is represented by strain in the chamber shown in Fig. 3. This assumes that the chamber is not pre-stressed. The maximum vertical aperture, $\mathbf{A}_{\mathrm{V}}$, is:

$$
\mathbf{A}_{\mathrm{V}}=\mathrm{h}-2 \mathrm{t}-2 \mathbf{y}_{\mathrm{m}} \text {. }
$$


Setting $\partial \mathbf{A}_{\mathrm{V}} / \partial \mathbf{t}=0$, we find the maximum vertical aperture by the relationship:

$$
t=3 \mathbf{Y}_{\mathrm{m}} \text {. }
$$

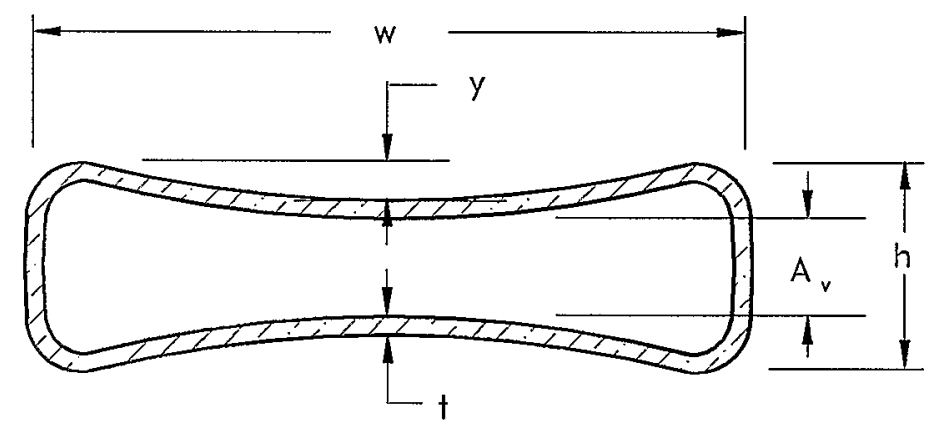

Figure 3. Strain In Dipole Chamber Due To Atmospheric Pressure

For the geometry given in Fig. 3, for $\mathrm{Al}, \mathbf{A}_{\mathrm{V}} \approx 30.2 \mathrm{~mm}$, and for stainless steel $\mathrm{A}_{\mathrm{V}} \approx 32.6$ $\mathrm{mm}$. This is unacceptable as the implication is that we have wasted $\approx 25 \%$ of the magnet gap with beam chamber deflection and thickness. Therefore, we must prestress the chamber in the dipole magnets, and seek a much thinner chamber wall, within the limits of the strength of the material chosen.

A chamber with a cross-section similar to that shown in Fig. 4 will deflect under atmospheric loading so as to just fit within the dipole gap. For a chamber of $t \approx 1.5 \mathrm{~mm}$, the stress on the chamber will be $\mathbf{s} \approx 2.27 \times 10^{5} \mathrm{kN} / \mathrm{m}^{2}$ (i.e., $33 \mathrm{kpsi}$ ). The chambers will be constructed of $304 \mathrm{~L}$ stainless steel and not be annealed. Therefore, these numbers seem acceptable.

Some sort of coating should be put on the dipole magnet pole faces to protect the beam chambers from the Fe used as pole material. If the chambers are rubbed or scratched against the pole faces, they will cease to be "stainless" and will be subject to corrosion.

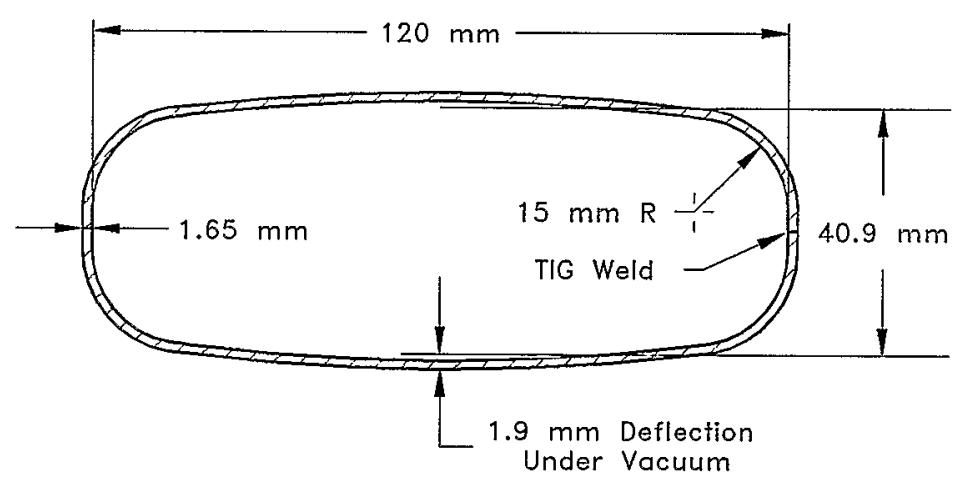

Figure 4. Required Dipole Chamber Shape For Maximum Verticle Beam Aperture When Chamber Is Strained By Vacuum Loading 


\section{Chamber Pumping During Beam Operation}

Several options exist for pumping the dipole magnet chambers. These include:

1. Use of distributed NEG pumps, and a "scattering" of small sputter-ion pumps around the stretcher to pump noble gases and the saturated hydrocarbons (i.e., gases not pumped by NEG pumps).

2. Use of sputter-ion pumps (only) between each of the dipole magnets.

3. Use of distributed sputter-ion pumps making use of the fringing field of the dipole magnets.

Option 1 would probably be too costly if we were to use st. stl. dipole chambers. It would have efficacy, were we able to use extruded $\mathrm{Al}$ dipole chambers. For reasons including chamber longitudinal impedance considerations, it would be advisable to extrude a separate channel, parallel with the beam chamber, to house the NEG strip. The chamber's major wall dimension would be too broad for a single chamber.

Transverse (i.e. to the beam) holes could be drilled between the two chambers for conductance coupling. Also, because of NEG bakeout requirements, a third water cooling chamber would have to be extruded, parallel with the NEG and beam chambers. This would have to be done because of the poor hot strength of $\mathrm{Al}$, as excessive chamber temperatures which would result from NEG bakeout. These considerations and findings of Section II, make use of Option 1 questionable.

Option 3 is "clever" and has found wide application in electron storage rings where one needs to pump gas desorbed by synchrotron radiation along a dipole magnet chamber. However, it presents unnecessarily complex fabrication problems (i.e., in our application), the need of electrostatically shielding the beam from the pump anode arrays, and makes difficult the servicing of the distributed sputter-ion pumps.

Option 2 is adopted for use in the Stretcher. Assume that these pumps are separated by a length $2 \ell$, where $2 \ell$ is the length of one half-cell. It can be shown that the pressure along an outgassing half-cell is given by:

$$
\mathbf{P}(\mathbf{x})=\mathbf{P}_{\mathrm{p}}+\frac{\pi \mathbf{q}}{2 k \mathrm{D}^{2}}\left(2 \mathbf{x} \ell-\mathbf{x}^{2}\right)
$$

$$
\begin{aligned}
& \text { where } \quad \mathbf{P}_{\mathrm{p}}=\text { the pump pressure, Torr, } \\
& \mathrm{q}=\text { chamber outgassing rate, Torr }-\ell / \mathrm{sec}-\mathrm{cm}^{2} \text {, } \\
& \ell=\text { length from the pump to the center of magnet, } \mathrm{cm} \text {, } \\
& \mathrm{D}=\text { equivalent diameter of the chamber, } \mathrm{cm} \text {, and } \\
& \mathrm{k}=\text { is a constant relating to the molecular weight and temperature of the } \\
& \text { numerical value of } 12.1 \text {, assuming an amu of } 28 \text {, and that the gas is at } \\
& 293^{\circ} \mathrm{K} \text {. }
\end{aligned}
$$


The average pressure in a sector (and the complete Stretcher), $\mathbf{P}_{\mathrm{avg} .}$, is then just:

$$
\begin{aligned}
\mathbf{P}_{\text {avg. }} & =\int_{0}^{\ell} \mathbf{P}(\mathbf{x}) \mathrm{d} \mathbf{x} \\
& =\mathbf{P}_{\mathrm{p}}+\left[\frac{\pi \mathbf{q} \ell^{2}}{3 \mathrm{k} \mathbf{D}^{2}}\right],
\end{aligned}
$$

Assuming that $\mathbf{D}=2((\mathbf{h}-2 \mathbf{t})(\mathbf{w}-2 \mathrm{t}) / \pi))^{\frac{1}{2}}$, in (6), (i.e., the rectangular chamber has an equivalent diameter, $\mathrm{D})$, is accurate to within $\approx 15 \%$.

$$
\begin{aligned}
& \text { If } \mathrm{w}=12.0 \mathrm{~cm} \text {, } \\
& \mathrm{h}=4.0 \mathrm{~cm} \text {, } \\
& t=0.23 \mathrm{~cm} \text {, the chamber wall thickness, } \\
& \text { then } \quad \mathrm{D} \approx 7.0 \mathrm{~cm} \text {. }
\end{aligned}
$$

Assuming a fairly clean system, an outgassing rate of $\mathrm{q} \approx 10^{-11}$ Torr- $\mathscr{L} / \mathrm{sec}-\mathrm{cm}^{2}$ is within reason, after $10^{3}$ hours of pumping. Use of $60 \mathscr{L} / \mathrm{sec}$ sputter-ion pumps will result in an average Stretcher pressure of $\approx 7 \times 10^{-9}$ Torr after $10^{3}$ hours of pumping.

For optimum longitudinal beam impedance, a smooth, beam-tube transition is desirable between the magnet chambers and the straight sections. For cost reasons, the transition is accomplished at each of the dipole chamber ends. This "keeps us out of a mill" in the manufacture of most of the Stretcher flanges.

\section{Sector Roughing Stations}

We have assumed that there will be no stretcher vacuum roughing stations resident in the "ring". There is some evidence that roughing stations resident in the AGS are not essential to machine operation, and cause problems when improperly operated. For example, there was no instance in FY'88 where use of the resident "turbo" roughing stations saved experimental machine time. However, there is considerable evidence that their improper use, in times of emergency, resulted in serious hydrocarbon contamination of the AGS.

For this reason, and to eliminate unnecessary costs, portable Sector Roughing/Leak Checking Carts be constructed for use during maintenance and on those rare occasions when the sputter-ion pumps need augmentation. In the latter case, vacuum technicians will be "called in" to position and set up the portable roughing carts.

In determining the length of each vacuum sector, we must address only one issue: "How long are we willing to wait from the start of a sector pump-down until machine turn-on?" Each time a vacuum sector is vented to atmospheric pressure, the walls of the chambers and components are contaminated with gas. Were this gas exclusively $\mathrm{N}_{2}$, on subsequent pumpdown, the walls would outgas very rapidly (i.e., in a matter of minutes), and the ion pumps could be quickly restarted. Unfortunately, this usually is not the case; that is, though 
an AGS sector may be vented to pure $\mathrm{N}_{2}$, air, including $\mathrm{H}_{2} \mathrm{O}$, gets inside of the vented sector. As a consequence, it usually takes hours to pump down a sector to the point where the ion pumps can be turned on. After this, it takes an hour or so to "condition" the pumps.

A new ion pump, pumping on a "clean and dry" system, is easily started at an $\mathrm{N}_{2}$ pressure of a few miliTorr. However, these are unrealistic conditions. If a pump and system has been exposed to air, starting the pump can be "tricky" business. To minimize pump maintenance and facilitate reliable starting, it is best to follow certain starting procedures. This involves initially turning on the pumps at a pressure of $\approx 5 \times 10^{-5}$ Torr; leaving them on for 10 minutes; shutting them off for 10 minutes; etc. This is called "conditioning" the pumps. Actually, the process involves controlling the desorption of surface gases on the pump elements, while avoiding both glow discharge in the pumps and thermal run-away.

Assume that the Stretcher is divided into Vacuum Sectors, each of which is isolated by in-line sector valves. Assume that each of these sectors is divided into $2 \mathbf{n}$ half-cells, and a half-cell is $2 \ell$ meters long. The pressure profile in an outgassing sector may be expressed by the following equation:

$$
P(x, t)=P_{p}+\frac{\pi q(t)}{2 k D^{2}}\left(2 x L-x^{2}\right)
$$

where $\mathbf{L}=2 \mathbf{n} \ell$. Assuming that $\mathbf{q}(t) \neq f(P)$, the pressure at the ion pump furthest removed from the sector roughing cart is simply:

$$
P(L, t)=P_{r}+\frac{\pi q(t)}{2 k D^{2}} L^{2}
$$

The pressure at the portable roughing pump, $\mathbf{P}_{\mathbf{r}}$, is simply the outgassing rate of one complete vacuum sector, divided by the rough pump speed. Substituting this into (8), results in a quadratic equation in $\mathbf{L}$ having only one root, which makes physical sense:

$$
\mathbf{L}=-\frac{4 k D^{3}}{2 \mathbf{S}_{r}}\left[1-\left[1+\frac{\mathbf{P}(\mathbf{L})\left(\mathbf{S}_{r}\right)^{2}}{4 \pi \mathbf{q}(\mathbf{t}) k \mathbf{D}^{4}}\right]^{\frac{1}{2}}\right],
$$

$$
\begin{aligned}
& \text { where, } \mathbf{P}(\mathbf{L})=\text { the tolerable starting pressure of an } \\
& \text { ion pump located distance } \mathbf{L} \text { form the } \\
& \text { roughing pump, } \\
& \text { and } \quad \mathbf{q}(t)=\text { the outgassing rate in Torr- } \mathscr{L} / \mathrm{sec}-\mathrm{cm}^{2} \\
& \text { as a function of time. }
\end{aligned}
$$

Assuming $\mathrm{q}(50 \mathrm{hr} \cdot) \approx 2.5 \times 10^{-11}$ Torr $-\mathscr{L} / \mathrm{sec}-\mathrm{cm}^{2}$, and that the source of outgassing is metal walls, rather than elastomers, plastics, etc., $q(t)$ may be approximated by the 
following equation:

$$
q(t) \approx q(500 h r \cdot)\left[\frac{t}{500 h r}\right]^{-m}
$$

where $\boldsymbol{m} \approx 0.9$, and $t>1.0 \mathrm{hr}$. Using (10) in (9), and assuming different the ion pump starting pressures, we can calculate, with (9), the time it will take to pump on a sector, prior to starting the ion pumps, as a function of the speed of the turbo-pump, $\mathbf{s}_{r}$, and the length, $\mathrm{L}$, of a half-sector. These results are given in Fig. 5, assuming use of a $100 \mathscr{L} / \mathrm{sec}$ roughing pump. It appears, with a clean system, with $\mathbf{n}=2$, conditioning of the sputter-ion pumps may be started in two to three hours. The benefits of proper system venting, and maintaining a clean system are dramatically illustrated in Fig. 5.

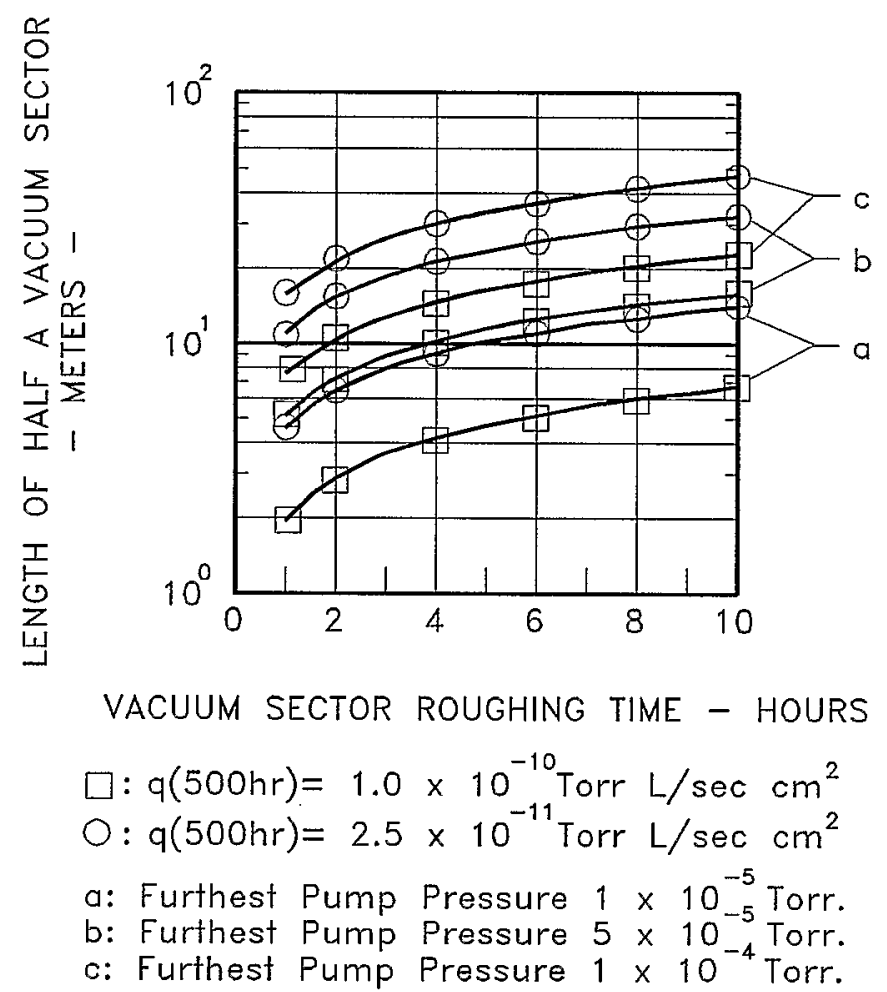

Figure 5. Pressure at the Sputter-Ion Pump Furthest Removed From the Sector Roughing Pump as a Function of Time and Assumed Beam Pipe Outgassing Rates.

This analysis indicates that Sector Valves should be located every other cell (i.e., $\approx 37.5$ $\mathrm{m}$ apart). Roughing Valves and Vacuum Instrument "Trees" will be placed at the mid-point between the Sector Valves. An example of a straight section configuration between two dipole magnets is shown in Fig. 6. Sector Valves and Instrument Trees will never be located in the same straight section. However, between each dipole magnet, the single $317.5 \mathrm{~mm}$ straight section, shown to the right in Fig. 6, must be reserved for some form of vacuum equipment. 


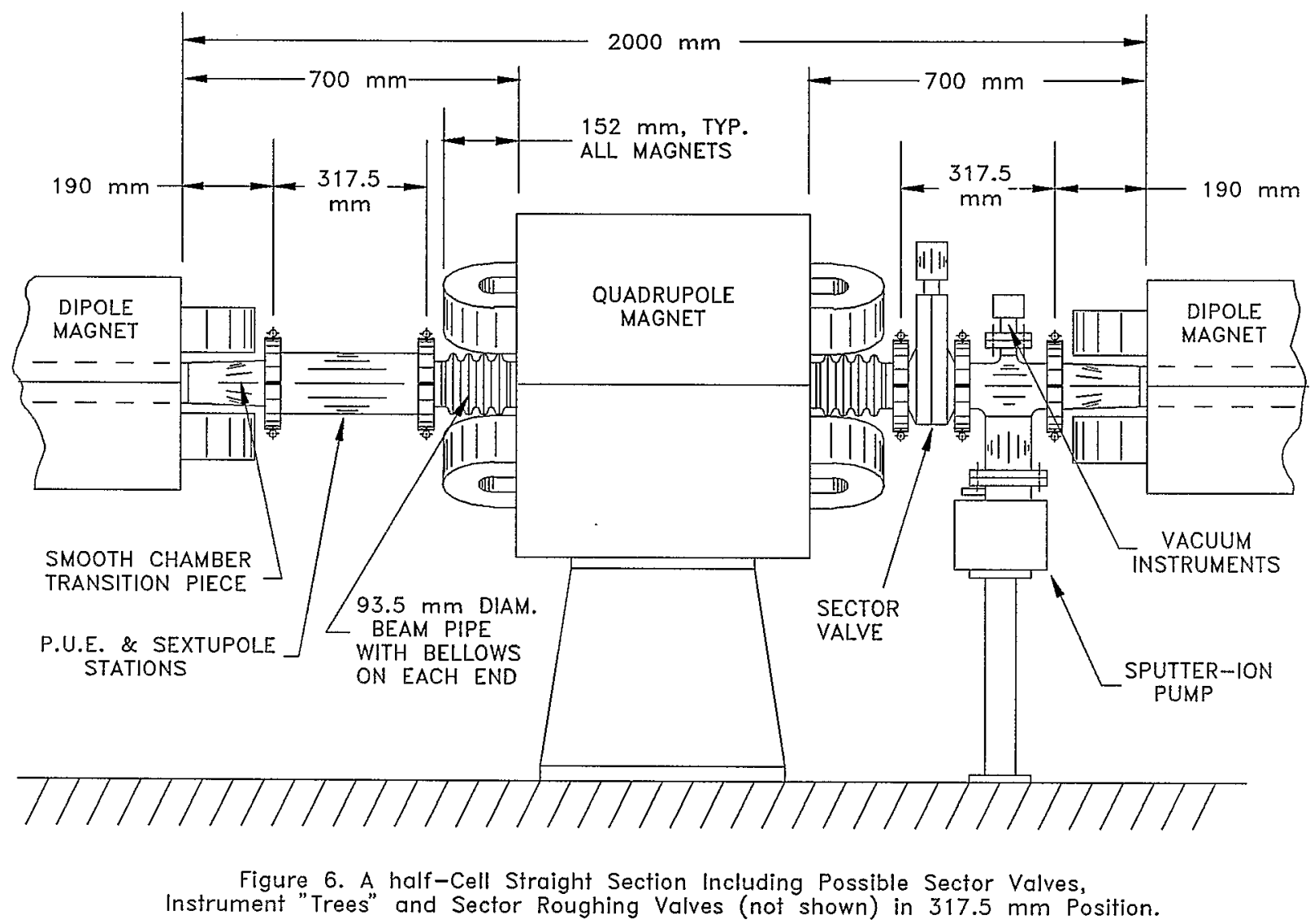

\section{Vacuum System Instrumentation and Controls}

A vacuum instrumentation \& control system architecture similar to that presently used in the AGS will be adopted in the Stretcher. A functional block diagram of the Stretcher I\&C system is shown in Fig. 7. Commercial sputter-ion pump power supplies, and ionization and Pirani gauge controllers will be purchased. Products presently are offered in the marketplace with RS-232 interface features. Engineering will be dedicated to designing interface "boxes" which allow communications between the commercial equipment and controllers, of the type presently existing in the various AGS "houses". Similar controllers will be located in three or four Stretcher "houses".

No permanent electronic hardware chassis will be resident in the tunnel. However, a form of ring communications buss will be installed. It is important that there be $20-30$ bus access ports about the Stretcher, though only two or three would ever be simultaneously used during maintenance work. It was suggested by R. Frankel that it would be possible to communicate with an Apollo equivalent by using a simple coaxial cable for this bus. Data would be communicated by frequency modulating carrier frequencies unique to two or three local, transportable controllers (LTCs). In this manner, the simultaneous communications from more than one LTC would be possible during maintenance periods. 


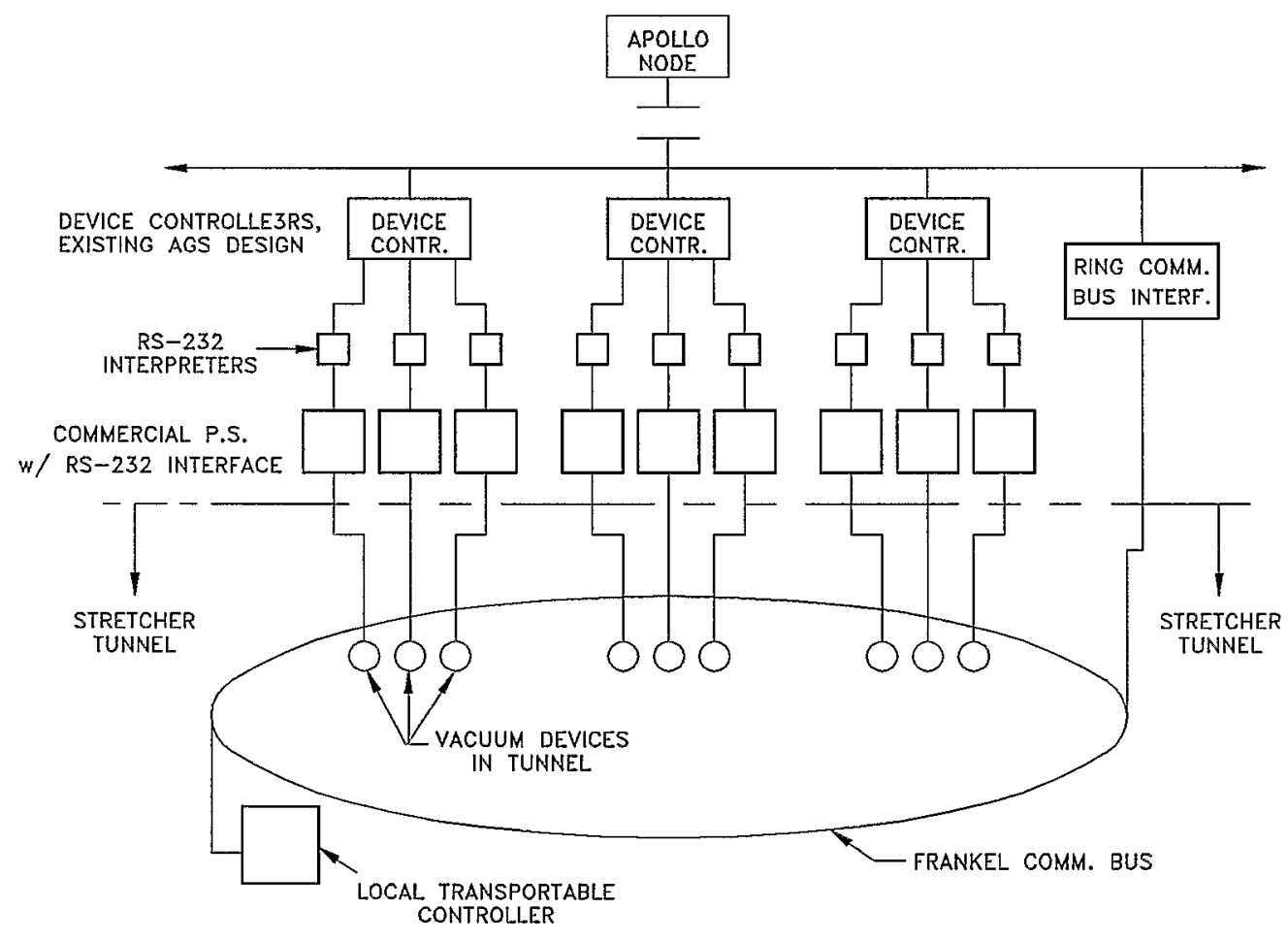

Figure 7. Stretcher Vacuum Instrumentation and Control System

\section{System Costs}

System costs are summarized in the attached Tables V - IX. We were able to draw extensively from recent AGS vacuum component development work in estimating costs for the Stretcher vacuum system. Much of the hardware used in the Stretcher will be common to both the AGS and the Stretcher. Approximations made in these estimates include use of $\approx 9.37 \mathrm{~m}$ straight sections, each paired with shorter straight sections/bellows assemblies identical to the one shown captured in the quadrupole in Fig. 6. Also, straight sections will be divided into sectors comparable in length and with similar equipment as the Stretcher "ring" is configured (i.e., sputter-ion pumps, gauges, roughing ports, etc.). 
Pressure: $1.47 \mathrm{E}+01 \mathrm{psi}$

Mag Gap: $1.62 \mathrm{E}+00$

Height: $1.61 \mathrm{E}+00$ inches

Modulus $2.77 \mathrm{E}+07$ (stainless: $27.7 \times 10^{\wedge} 6$; aluminum: $10.3 \times 10^{\wedge} 6$ )

TABLE I

Maximum Chamber Deflection At Center, Stainless Chamber

width in $\mathrm{mm}-\cdots>\quad 9.00 \mathrm{E}+01 \quad 1.00 \mathrm{E}+02 \quad 1.10 \mathrm{E}+02 \quad 1.20 \mathrm{E}+02 \quad 1.30 \mathrm{E}+02 \quad 1.40 \mathrm{E}+02 \quad 1.50 \mathrm{E}+02$

width in inches..$->\quad 3.54 \mathrm{E}+00 \quad 3.94 \mathrm{E}+00 \quad 4.33 \mathrm{E}+00 \quad 4.72 \mathrm{E}+00 \quad 5.12 \mathrm{E}+00 \quad 5.51 \mathrm{E}+00 \quad 5.91 \mathrm{E}+00$ thickness "t"

$\mathrm{mm}$ inches

4.70E+00 1.85E-01 3.31E-03 5.06E-03 7.43E-03 1.06E-02 1.46E-02 1.98E-02 2.61E-02

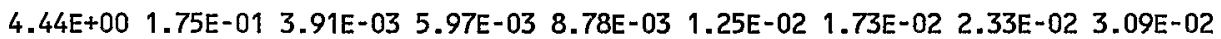

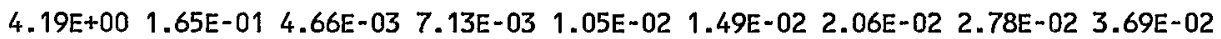

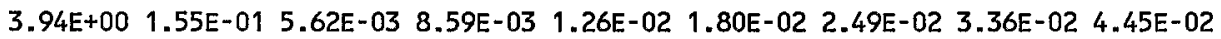
3.68E+00 1.45E-01 6.87E-03 1.05E-02 1.54E-02 2.20E-02 3.04E-02 4.10E-02 5.43E-02 3.43E+00 1.35E-01 8.51E-03 1.30E-02 1.91E-02 2.72E-02 3.76E-02 5.08E-02 6.73E-02 3.17E+00 1.25E-01 1.07E-02 1.64E-02 2.41E-02 3.43E-02 4.74E-02 6.40E-02 8.48E-02 $2.92 \mathrm{E}+00 \quad 1.15 \mathrm{E}-01 \quad 1.38 \mathrm{E}-02 \quad 2.10 \mathrm{E}-02 \quad 3.09 \mathrm{E}-02 \quad 4.40 \mathrm{E}-02 \quad 6.09 \mathrm{E}-02 \quad 8.23 \mathrm{E}-02$ 1.09E-01 2.67E+00 1.05E-01 1.81E-02 2.76E-02 4.06E-02 5.78E-02 8.00E-02 1.08E-01 1.43E-01 2.41E+00 9.50E-02 2.44E-02 3.73E-02 5.49E-02 7.81E-02 1.08E-01 1.46E-01 1.93E-01 2.16E+00 8.50E-02 3.41E-02 5.21E-02 7.66E-02 1.09E-01 1.51E-01 2.04E-01 2.70E-01

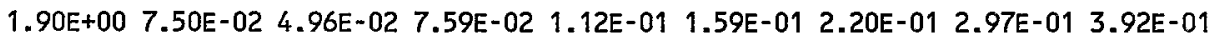
1.65E+00 6.50E-02 7.62E-02 1.17E-01 1.71E-01 2.44E-01 3.37E-01 4.56E-01 6.03E-01 $1.40 \mathrm{E}+00$ 5.50E-02 1.26E-01 1.92E-01 2.83E-01 4.02E-01 5.57E-01 7.52E-01 9.95E-01

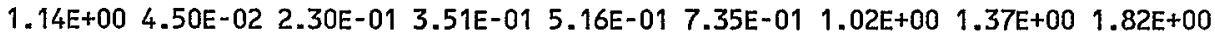

TABLE II

Maximum Chamber Stress, Stainless Chamber

width in $\mathrm{cm} \cdots . .-9.00 \mathrm{E}+00 \quad 1.00 \mathrm{E}+01 \quad 1.10 \mathrm{E}+01 \quad 1.20 \mathrm{E}+01 \quad 1.30 \mathrm{E}+01 \quad 1.40 \mathrm{E}+01 \quad 1.50 \mathrm{E}+01$ width in inches $\ldots . .-3.54 E+00 \quad 3.94 E+00 \quad 4.33 E+00 \quad 4.72 E+00 \quad 5.12 E+00 \quad 5.51 E+00 \quad 5.91 E+00$ thickness "t"

min inches

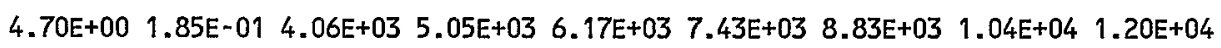

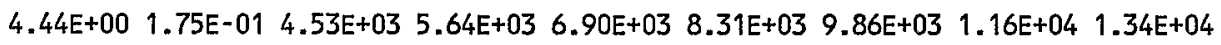
4.19E+00 1.65E-01 $5.10 E+03 \quad 6.35 E+03 \quad 7.76 E+03 \quad 9.34 E+03 \quad 1.11 E+04 \quad 1.30 E+04 \quad 1.51 E+04$ $3.94 E+00 \quad 1.55 E-01 \quad 5.78 E+03 \quad 7.19 E+03 \quad 8.80 E+03 \quad 1.06 E+04 \quad 1.26 E+04 \quad 1.47 E+04 \quad 1.71 E+04$

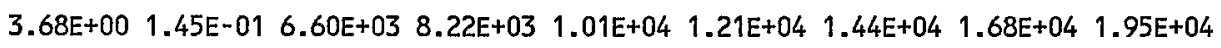
$3.43 E+001.35 E-01 \quad 7.62 E+03 \quad 9.48 E+03 \quad 1.16 E+04 \quad 1.40 E+04 \quad 1.66 E+04 \quad 1.94 E+04 \quad 2.26 E+04$

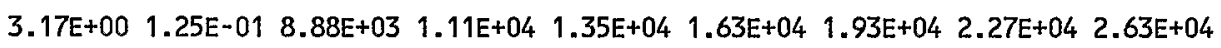

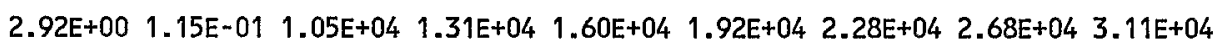

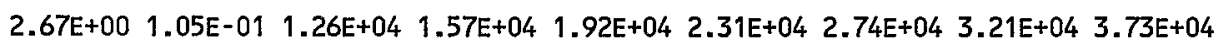
$2.41 E+00 \quad 9.50 E-02 \quad 1.54 E+04 \quad 1.91 E+04 \quad 2.34 E+04 \quad 2.82 E+04 \quad 3.35 E+04 \quad 3.93 E+04 \quad 4.55 E+04$ 2.16E+00 8.50E-02 1.92E+04 2.39E+04 2.92E+04 3.52E+04 4.18E+04 4.90E+04 5.69E+04

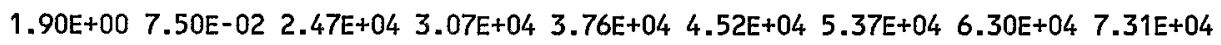

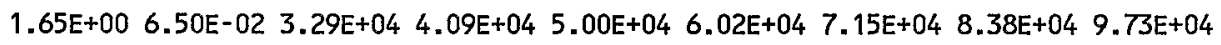

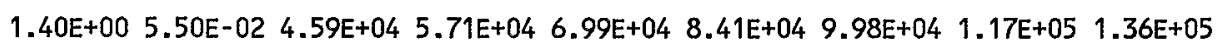

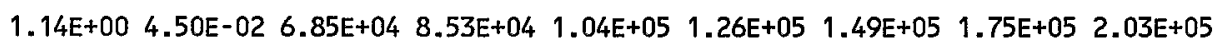


$\begin{array}{ll}\text { Pressure: } 1.47 \mathrm{E}+01 \text { psi } & \text { Tuozzolo/Welch } \\ \text { Mag Gap: } 1.62 \mathrm{E}+00 & \text { February 3, } 1989 \\ \text { Height: } 1.61 \mathrm{E}+00 \text { inches } & \\ \text { Modulus } 1.03 \mathrm{E}+07 \text { (stainless: } 27.7 \times 10^{\wedge} 6 \text {; } & \text { aluminum: } 10.3 \times 10^{\wedge} 6 \text { ) }\end{array}$

TABLE III

Maximum Chamber Deflection At Center, Aluminum Chamber

width in $\mathrm{mm}-\cdots \rightarrow \quad 9.00 \mathrm{E}+01 \quad 1.00 \mathrm{E}+02 \quad 1.10 \mathrm{E}+02 \quad 1.20 \mathrm{E}+02 \quad 1.30 \mathrm{E}+02 \quad 1.40 \mathrm{E}+02 \quad 1.50 \mathrm{E}+02$ width in inches --.> $\quad 3.54 E+00 \quad 3.94 E+00 \quad 4.33 E+00 \quad 4.72 E+00 \quad 5.12 E+00 \quad 5.51 E+00 \quad 5.91 E+00$ thickness "t"

$\mathrm{mm}$ inches

4.70E+00 1.85E-01 8.89E-03 1.36E-02 2.00E-02 2.84E-02 3.93E-02 5.31E-02 7.03E-02 4.44E+00 1.75E-01 1.05E-02 1.61E-02 2.36E-02 3.36E-02 4.65E-02 6.28E-02 8.31E-02 4.19E+00 1.65E-01 1.25E-02 1.92E-02 2.82E-02 4.01E-02 5.54E-02 7.49E-02 9.91E-02 3.94E+00 1.55E-01 1.51E-02 2.31E-02 3.40E-02 4.83E-02 6.69E-02 9.03E-02 1.20E-01 3.68E+00 1.45E-01 1.85E-02 2.82E-02 4.15E-02 5.90E-02 8.17E-02 1.10E-01 1.46E-01 3.43E+00 1.35E-01 2.29E-02 3.50E-02 5.14E-02 7.32E-02 1.01E-01 1.37E-01 1.81E-01 3.17E+00 1.25E-01 2.88E-02 4.41E-02 6.48E-02 9.22E-02 1.28E-01 1.72E-01 2.28E-01 $2.92 \mathrm{E}+00 \quad 1.15 \mathrm{E}-01 \quad 3.70 \mathrm{E}-02$ 5.66E-02 8.32E-02 $1.18 \mathrm{E}-01 \quad 1.64 \mathrm{E}-01 \quad 2.21 \mathrm{E}-01 \quad 2.93 \mathrm{E}-01$ 2.67E+00 1.05E-01 4.86E-02 7.44E-02 1.09E-01 1.55E-01 2.15E-01 2.91E-01 3.85E-01 2.41E+00 9.50E-02 6.57E-02 1.00E-01 1.48E-01 2.10E-01 2.90E-01 3.92E-01 5.19E-01 2.16E+00 8.50E-02 9.17E-02 1.40E-01 2.06E-01 2.93E-01 4.06E-01 5.48E-01 7.25E-01 $1.90 \mathrm{E}+00$ 7.50E-02 1.33E-01 2.04E-01 3.00E-01 4.27E-01 5.90E-01 7.97E-01 1.06E+00 $1.65 \mathrm{E}+00 \quad 6.50 \mathrm{E}-02$ 2.05E-01 3.13E-01 4.61E-01 6.55E-01 9.07E-01 1.23E+00 1.62E+00

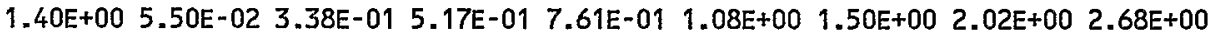

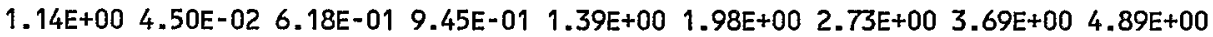

TABLE IV

Maximum Chamber Stress, Aluminum Chamber

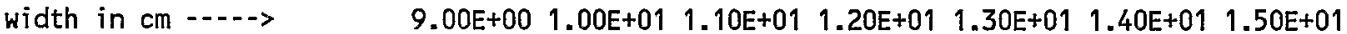
width in inches $\cdots-\cdots 3.54 \mathrm{E}+00 \quad 3.94 \mathrm{E}+00 \quad 4.33 \mathrm{E}+00 \quad 4.72 \mathrm{E}+00 \quad 5.12 \mathrm{E}+00 \quad 5.51 \mathrm{E}+00 \quad 5.91 \mathrm{E}+00$ thickness "t"

$\mathrm{mm}$ inches

4.70E+00 1.85E-01 4.06E+03 5.05E+03 $6.17 E+03 \quad 7.43 E+03 \quad 8.83 E+03 \quad 1.04 E+04 \quad 1.20 E+04$

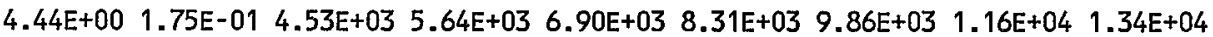
4.19E+00 1.65E-01 $5.10 E+03 \quad 6.35 E+03 \quad 7.76 E+03 \quad 9.34 E+03 \quad 1.11 E+04 \quad 1.30 E+04 \quad 1.51 E+04$ 3.94E+00 1.55E-01 $5.78 E+03 \quad 7.19 E+03 \quad 8.80 E+03 \quad 1.06 E+04 \quad 1.26 E+04 \quad 1.47 E+04 \quad 1.71 E+04$ $3.68 E+00 \quad 1.45 E-01 \quad 6.60 E+03 \quad 8.22 E+03 \quad 1.01 E+04 \quad 1.21 E+04 \quad 1.44 E+04 \quad 1.68 E+04 \quad 1.95 E+04$ $3.43 E+00 \quad 1.35 E-01 \quad 7.62 E+03 \quad 9.48 E+03 \quad 1.16 E+04 \quad 1.40 E+04 \quad 1.66 E+04 \quad 1.94 E+04 \quad 2.26 E+04$

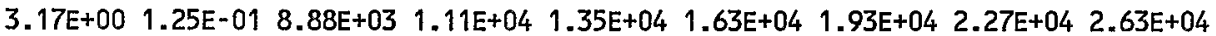
$2.92 E+001.15 E-01 \quad 1.05 E+04 \quad 1.31 E+04 \quad 1.60 E+04 \quad 1.92 E+04 \quad 2.28 E+04 \quad 2.68 E+04 \quad 3.11 E+04$ 2.67E+00 1.05E-01 1.26E+04 1.57E+04 1.92E+04 2.31E+04 2.74E+04 $3.21 E+04 \quad 3.73 E+04$ $2.41 E+00 \quad 9.50 E-02 \quad 1.54 E+04 \quad 1.91 E+04 \quad 2.34 E+04 \quad 2.82 E+04 \quad 3.35 E+04 \quad 3.93 E+04 \quad 4.55 E+04$ $2.16 E+00 \quad 8.50 E-02 \quad 1.92 E+04 \quad 2.39 E+04 \quad 2.92 E+04 \quad 3.52 E+04 \quad 4.18 E+04 \quad 4.90 E+04 \quad 5.69 E+04$ $1.90 E+00 \quad 7.50 E-02 \quad 2.47 E+04 \quad 3.07 E+04 \quad 3.76 E+04 \quad 4.52 E+04 \quad 5.37 E+04 \quad 6.30 E+04 \quad 7.31 E+04$

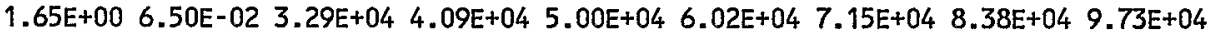

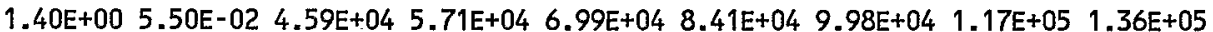

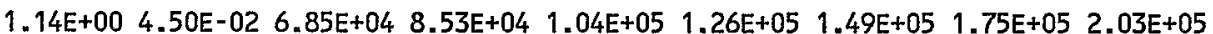


TABLE V

Decenber 19,1988

Rev. 8

ITBH

ACTIVITY OR ITBH

\section{STBETCHBR VACUUH SYSTBH COST BSTIMATB}

CHAMBBRS
Rino H. Welch

Joseph Tuozzolo

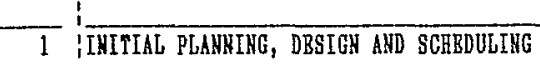

- 2 DIPOLB CHAMBRES, STANDARD

3 DIPOLB CHAMBBRS, SPBCIAL

( 1 STRAIGHT SBCTIOHS, $(9.37 \mathrm{a}$

- 5 PRAKSITIONS (SBZTAPOLB/PUB'S).

- 6 iTUBB/BBLLORS ASS'T, QUADS

- 7 CROSB, 4-IMCH, IP, BOUGHIMG AHD BBAHLIHB.

-

TABLE VI

Rev. B

\section{SPRBTCHRB VACUUY STSTBM COST BSTIHATB}

PUHPS

\begin{tabular}{|c|c|}
\hline $\begin{array}{l}\text { ITBH } \\
\text { Ho. }\end{array}$ & ACPIVIPY OB ITBH \\
\hline 9 & PUYP, 6OL/Sec SPUTYBR-IOH \\
\hline 10 & PUYPS, $200 \mathrm{~L} / \mathrm{sec}$ SPUTPRR-ION (2/BBAH COHPOHBMT CLAYBBR) \\
\hline 11 & PORTABLB BOUGHIHG AYD LBARCHBCEING SYSTEMS \\
\hline
\end{tabular}

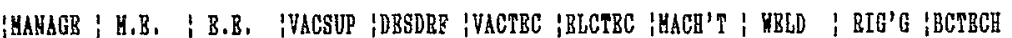

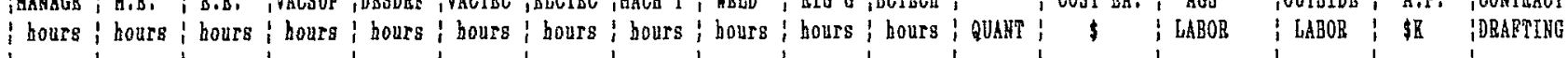

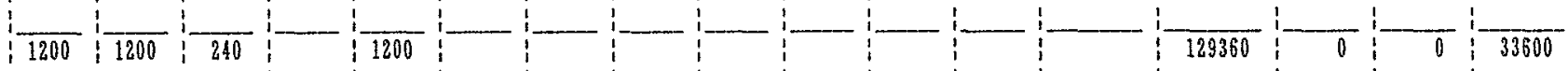

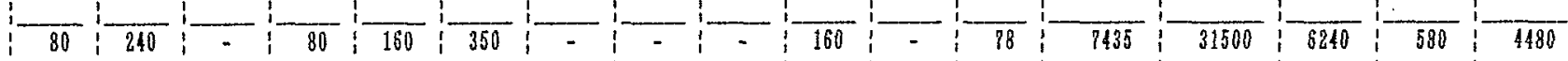

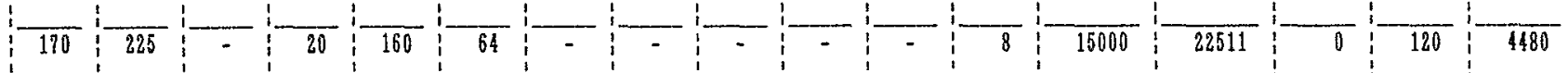

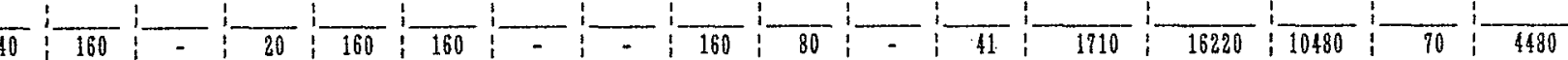

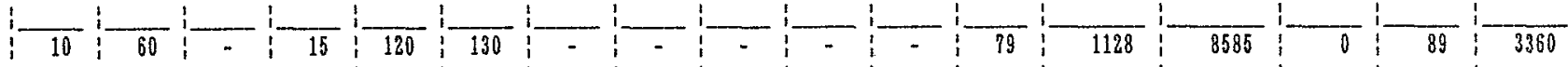

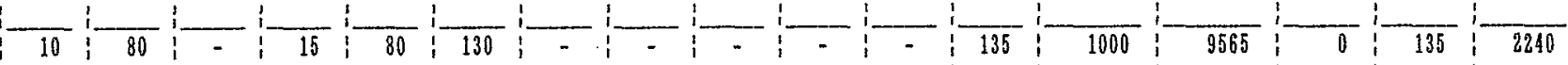

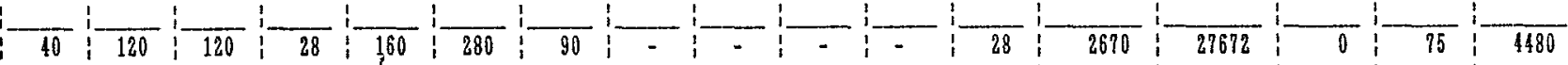

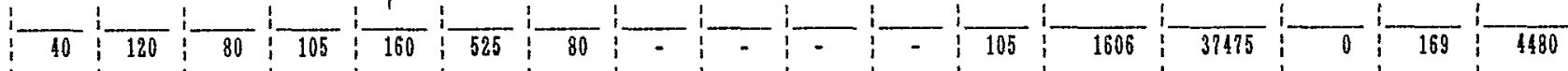

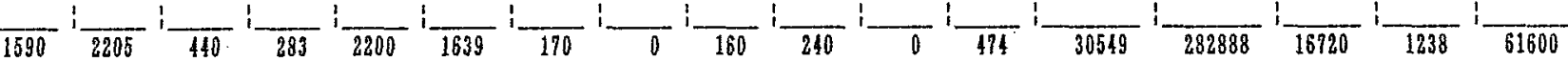

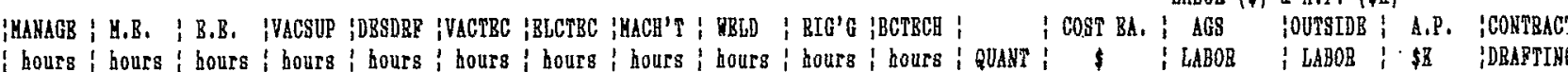

LABOB $(\$) \& A . P,(\$ R)$

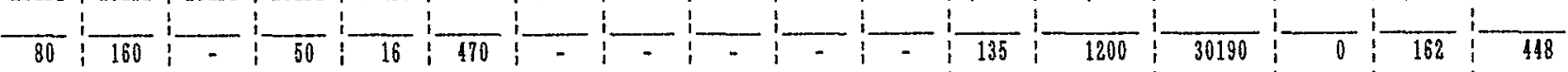

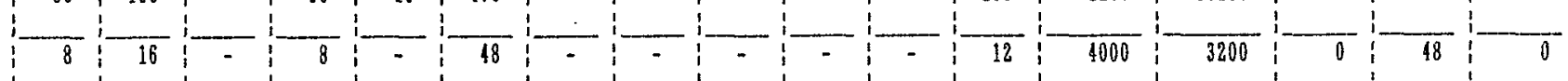

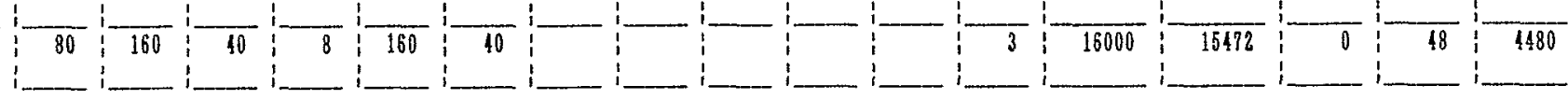


abreViated SCHEDULE OF MANPONER LOAdiNg FOR a GivEN PROJECT AS A FUNCTION OF JOB CLASSIFICATION

$$
\text { (rounded to integers) }
$$

Kino M. Welch

Dec. 22,1988

PROJECT NAME: STRETCHER MANPOHER ALLOCATION， REv. B

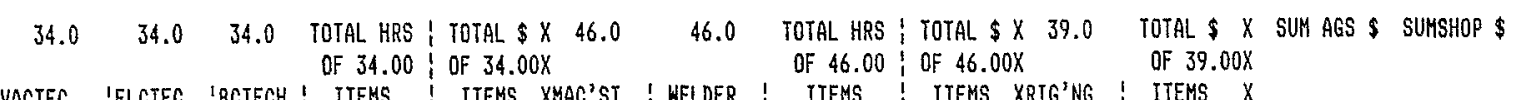
\begin{tabular}{c|c:c} 
ITOTAL HRS & TOTAL $\$ X$ \\
OF 49.00 & OF $49.00 \mathrm{X}$
\end{tabular}

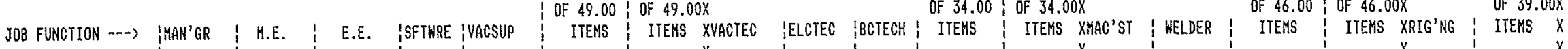

\begin{tabular}{|c|c|c|c|c|c|c|c|c|c|c|c|c|c|c|}
\hline & & & & & & & & & & & & $x$ & & \\
\hline TOTAL PROJECT & & & & & & & & & 85540 & 00 & & $\begin{array}{l}x \\
x\end{array}$ & $0 n$ & 1600 \\
\hline FUNGT'N HOURS & 2390.0 & 3669.0 & 4980.0 & 0.0 & 685.0 & & & $\begin{array}{l}x \quad 3215.0 \\
x\end{array}$ & 10004.0 & 0.0 & & $\hat{x}$ & 0.0 & $\$ 00.0$ \\
\hline PLAN \& SCHEDULE: & & & & & & & & $x$ & & & & $x$ & & \\
\hline & & & & & & & & $x$ & & & & $x^{x}$ & & \\
\hline$\%$ ALLOCATED & 45.0 & 15.0 & 15.0 & 15.0 & 10.0 & & & 5.0 & 5.0 & 3.0 & & $\begin{array}{l}x \\
x\end{array}$ & - & - \\
\hline PERSON HOURS & 1075.5 & 550.4 & 747.0 & 0.0 & 68.5 & 2441.4 & 119626.2 & $\times 163.8$ & 427.7 & 0.0 & 591.5 & $20109.3 \times$ & 0.0 & 0.0 \\
\hline
\end{tabular}

Petson

DESIGN

\begin{tabular}{l|l|l|l|l|l|l|l|l}
\hline \&ESIGN & & & & & & \\
\& ALLOCATED & 20.0 & 40.0 & 40.0 & 55.0 & 5.0 &
\end{tabular}

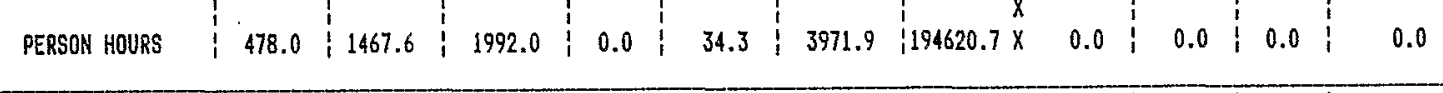

\begin{tabular}{l|r|r|r|r|r|r|r|r|}
\hline ACRUISITION: & & & & & & & \\
\& ALLOCATED & 25.0 & 25.0 & 25.0 & 10.0 & 10.0 & \\
PERSON HOURS & 597.5 & 917.3 & 1245.0 & 0.0 & 68.5 & 2828.3 & 138584.3
\end{tabular}

\begin{tabular}{|c|c|c|c|}
\hline$x$ & 1 & $x$ & \\
\hline$x$ & I & $x$ & \\
\hline$\times \quad 10.0$ & $10.0: 10.0$ & $\times 100.0$ & 100.0 \\
\hline
\end{tabular}

\begin{tabular}{l}
$x$ \\
$x$ \\
$x 1100.0$ \\
$x$ \\
\hline$x$ \\
$x$ \\
$x$ \\
$x$ \\
$x$
\end{tabular}

\begin{tabular}{l|l:l}
0.0 & $0.0 \times 55.0$ & $2145.0 \times 139735.5$
\end{tabular}

2145.0

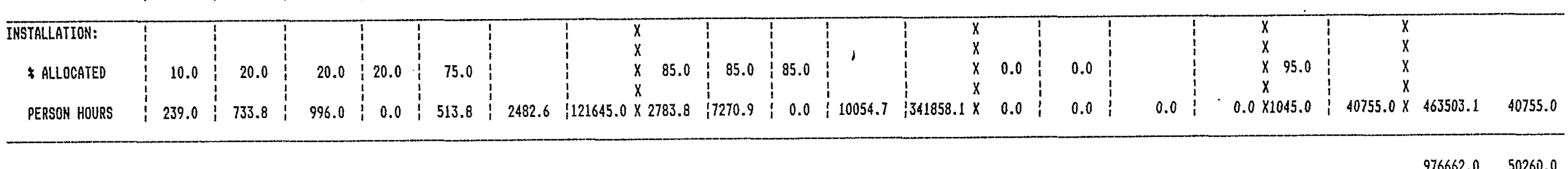

\section{LABOR COSTS}

TOTALS $\$ K$

NOTE: ASSUMED USE OF CONTRACT DRAFIING.

PLANNING \& SCHEDULING ...... 141.9

DESIGN (w/ CONTRACT DRAFT.) ... 334.8

ACQUISITION ................ 186.2

INSTALLATION \& TEST .......... 504.3

GRAND TOTAL SK $\overline{1167.1}$ 